\title{
Sensitivity and specificity of double-blinded penicillin skin testing in relation to oral provocation with amoxicillin in children
}

\author{
Roxane Labrosse ${ }^{1}$, Louis Paradis ${ }^{1,2}$, Kathryn Samaan ${ }^{1}$, Jonathan Lacombe-Barrios ${ }^{1}$, Jean Paradis², \\ Philippe Bégin ${ }^{1,2^{*}}$ (ID and Anne Des Roches ${ }^{1}$
}

\begin{abstract}
Current recommendations for the management of penicillin allergy are to perform penicillin skin testing (PST) with penicilloyl-polylysine (PPL) and benzylpenicillin (BP) prior to drug challenge with amoxicillin. However, the role of PST is increasingly questioned in the pediatric setting. To resolve the question of PST's diagnostic accuracy, consecutive children with a history of non-life-threatening penicillin allergy referred to a tertiary-care allergy center were recruited to undergo double-blinded PST with PPL and BP prior to drug provocation to amoxicillin. Five of 158 participants (3.2\%) presented with an immediate or accelerated reaction upon amoxicillin challenge, none of which were severe. Only one of these had positive PST (20\%), compared to 15 of 153 amoxicillin tolerant participants (9.8\%). The sensitivity and specificity of PST with PPL and BP for reacting upon amoxicillin challenge were $20 \%$ (95\% Cl: $0.5-$ $71.6 \%)$ and $90 \%$ (95\% Cl: 84.4-94.4\%), respectively. These results argue against the routine use of PST as a preliminary step to drug provocation with amoxicillin in this population, as it is unlikely to significantly alter pre-test probability of reacting to challenge.
\end{abstract}

Keywords: Penicillin allergy, Amoxicillin, Sensitivity, Specificity, Diagnostic accuracy, Skin testing

\section{To the editor}

The systematic recourse to penicillin skin tests (PST) to investigate penicillin allergy is increasingly questioned, especially in children with a history of isolated cutaneous reaction. This change was driven by both real-life cohort studies demonstrating the safety of direct challenge approaches as well as by diagnostic accuracy studies in which even patients with positive PST would undergo a confirmatory drug provocation test (DPT) [1-9]. The latter are of particular interest as they allow the calculation of sensitivity and specificity estimates, which are essential to perform cost-effectiveness analyses

\footnotetext{
*Correspondence: a.des.roches@umontreal.ca

${ }^{2}$ Allergy and Clinical Immunology, Centre Hospitalier de I'Université de Montréal (CHUM), 3175 Chemin de la Côte-Sainte-Catherine, Montreal, QC H3T 1C5, Canada

Full list of author information is available at the end of the article
}

and extrapolate results to other clinical contexts with different pre-test probabilities. However, in all studies to date, the reference test (DPT) was universally performed with knowledge of the index test results (PST) creating a risk of interpretation bias. In addition, three of the eight studies published since 2011 did not challenge all patients with positive PST, potentially leading to verification bias.

Here, we present the results of a diagnostic accuracy study on penicillin skin testing using a prospective double-blinded design circumventing the problem of verification and interpretation bias in order. Study population consisted in patients aged 0 to 18 years reporting a history of non-life-threatening reaction to penicillin including urticaria and/or a maculopapular rash and referred for evaluation at a tertiary-care pediatric allergy center. Specific exclusion criteria included a diagnosis or a history suggestive of a severe non-IgE mediated drug allergy including severe

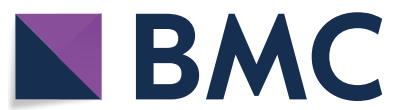

(c) The Author(s) 2020. This article is licensed under a Creative Commons Attribution 4.0 International License, which permits use, sharing, adaptation, distribution and reproduction in any medium or format, as long as you give appropriate credit to the original author(s) and the source, provide a link to the Creative Commons licence, and indicate if changes were made. The images or other third party material in this article are included in the article's Creative Commons licence, unless indicated otherwise in a credit line to the material. If material is not included in the article's Creative Commons licence and your intended use is not permitted by statutory regulation or exceeds the permitted use, you will need to obtain permission directly from the copyright holder. To view a copy of this licence, visit http://creativeco mmons.org/licenses/by/4.0/. The Creative Commons Public Domain Dedication waiver (http://creativecommons.org/publicdomain/ zero/1.0/) applies to the data made available in this article, unless otherwise stated in a credit line to the data. 
cutaneous adverse reactions (SCARs), an active infection at time of evaluation, uncontrolled asthma, and any concurrent medication intake that could interfere with skin testing (anti-histamines, omalizumab) or place the patient at risk during challenge (beta-blockers). Patients with a history of anaphylaxis were not excluded from the outset, unless the reaction was compatible with anaphylactic shock (hypotension, altered consciousness or cardiorespiratory arrest). Consecutive patients were prospectively invited to the study starting with the 1501st patient on the waiting list to avoid regular allergy clinic appointments competing with recruitment. All patients signed informed consent forms prior to their enrollment and the study received approval from the institution's ethics committee (CHUSJ-2013-495-3635).

Eligible participants underwent double-blinded skin testing using a method described previously [10]. Blinded PST reagents were prepared by an unblinded nurse (professional 1) in a random order that was sealed in an envelope, to be opened only at time of analysis. Testing was performed by a second nurse (professional 2) who was blinded to reagent order. Intradermal testing was performed on the volar face of the arm with penicilloylpolylysine (PPL) $6.0 \times 10^{-5} \mathrm{M}$ (PRE-PEN ${ }^{\circledR}$, AllerQuest, LLC, Plainville, CT), benzylpenicillin (BP) $10,000 \mathrm{UI} / \mathrm{mL}$ (Fresenius Kabi Canada Ltd, Richmond Hill, Ontario), BP $1000 \mathrm{IU} / \mathrm{mL}$ and saline, in random order. A prick test with histamine was used as positive control. Skin tests were read after $15 \mathrm{~min}$ by an allergist also blinded to the order of the tests (professional 3). The tests were then covered with towels to avoid influencing the second blinded allergist supervising the drug provocation (professional 4).

The graded drug provocation to amoxicillin $(45 / \mathrm{mg} /$ $\mathrm{kg}$ ) was performed in three incremental steps: $1 / 100$, $1 / 10$, and full dose at $30 \mathrm{~min}$ intervals followed by $1 \mathrm{~h}$ of observation to identify signs of IgE-mediated reaction. Participants were called to ensure the absence of accelerated reaction in the following $48 \mathrm{~h}$. The study planned for an initial sample size of 300 patients, based on the assumption of positive predictive value (PPV) of $25 \%$ and rate of positive PST of $10 \%$ [5]. PST was considered positive if either the PPL or BP $10,000 \mathrm{UI} / \mathrm{mL}$ generated a mean wheal diameter that was $3 \mathrm{~mm}$ greater than the negative control, with flare, as per practice parameter [11]. The sensitivity and specificity of PST were calculated in light of DPT results, which constitutes the gold standard for diagnosis of penicillin allergy. There were no pre-specified plans for subgroup analysis or rules for early termination.

Between October 2013 and June 2015, 213 patients were approached to participate in the study, of which 158 were enrolled and none of whom met exclusion criteria (Fig. 1). Demographic and clinical characteristics of participants are presented in Table 1. All participants completed the study.

The study was terminated following this interim analysis for cause of futility. Of the 16 patients with a positive intradermal PST (8.2\%), only one presented an immediate $(<6 \mathrm{~h})$ reaction on drug provocation

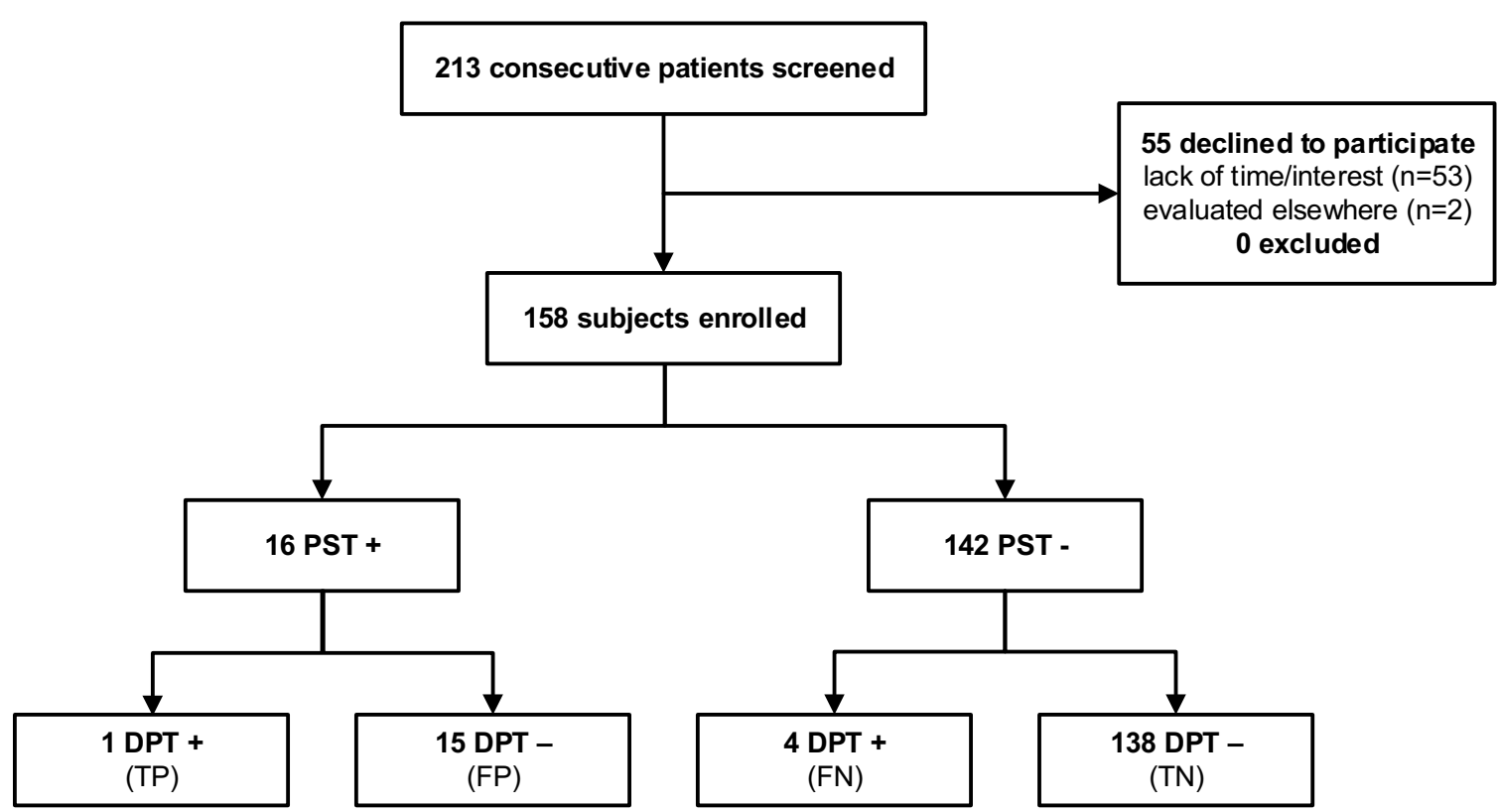

Fig. 1 Flowchart of patients enrolled in study with penicillin skin testing (PST) and drug provocation test (DPT) results 
Table 1 Participants' characteristics

\begin{tabular}{|c|c|}
\hline Number of patients & $n=158$ \\
\hline \multicolumn{2}{|l|}{ Age (years) } \\
\hline Mean (range) & $5.5(0.7-18.1)$ \\
\hline \multicolumn{2}{|l|}{ Gender, n (\%) } \\
\hline Male & $82(51.9)$ \\
\hline \multicolumn{2}{|l|}{ Personal history of atopy, n (\%) } \\
\hline Any atopic condition & $71(44.9)$ \\
\hline Atopic dermatitis & $47(29.7)$ \\
\hline Allergic rhinitis & $29(18.4)$ \\
\hline Asthma & $32(20.3)$ \\
\hline Food allergy & $8(5.1)$ \\
\hline Personal history of other drug allergy, n (\%) & $45(28.5)$ \\
\hline Family history of drug allergy, n (\%) & $50(31.6)$ \\
\hline \multicolumn{2}{|l|}{ Molecule of initial reaction, $\mathrm{n}(\%)$} \\
\hline Amoxicillin & $137(86.7)$ \\
\hline Amoxicillin/clavulinic acid & $13(8.2)$ \\
\hline Presumed amoxicillin & $6(3.8)$ \\
\hline Penicillin V & $1(0.6)$ \\
\hline Ampicillin & $1(0.6)$ \\
\hline \multicolumn{2}{|l|}{ Indication for antibiotic } \\
\hline Otitis media & $80(50.6 \%)$ \\
\hline Pharyngitis & $15(9.5 \%)$ \\
\hline Pneumonia/bronchitis & $10(6.3 \%)$ \\
\hline Sinusitis & $3(1.9 \%)$ \\
\hline Scarlet fever & $3(1.9 \%)$ \\
\hline Other & $11(7.0 \%)$ \\
\hline Unknown & $36(22.8 \%)$ \\
\hline \multicolumn{2}{|l|}{ Allergic reaction, n (\%) } \\
\hline Rash & $158(100.0)$ \\
\hline Urticaria & $59(37.3)$ \\
\hline Maculopapular rash & $89(56.3)$ \\
\hline Macular rash & $7(4.4)$ \\
\hline Undefined rash & $2(1.3)$ \\
\hline Angioedema & $11(7.0)$ \\
\hline Cough/bronchospasm & $2(1.3)$ \\
\hline Vomiting & $5(3.2)$ \\
\hline Anaphylaxis & $0(0.0)$ \\
\hline \multicolumn{2}{|l|}{ Timing of allergic reaction, $\mathrm{n}(\%)$} \\
\hline Within < $24 \mathrm{~h}$ & $27(17.1)$ \\
\hline After $>24 \mathrm{~h}$ & $99(62.7)$ \\
\hline Unknown & $32(20.3)$ \\
\hline $\begin{array}{l}\text { Time elapsed between initial reactions and allergy } \\
\text { workup, years (median, interquartile range) }\end{array}$ & $1.6(0.7-4.8)$ \\
\hline
\end{tabular}

(Table 2). In those with negative PST, two presented an immediate and two presented an accelerated (6 h-48 h) reaction upon drug provocation. All reactions were mild and limited to the skin and responded promptly to antihistamine treatment. Delayed PST reading was negative in all patients. The predictive value of PST was 6.3\% (95\%
CI: $0.4-26.3 \%)$. The observed sensitivity and specificity for IgE-mediated reactions (immediate or accelerated) were $20 \%$ (95\% CI $0.5-71.6 \%$ ) and $90 \%$ (95\% CI $84.4-$ $94.4 \%)$, respectively. The decision to terminate the study was made by the investigators following discussion with the ethics committee and was based on the rationale that even if sensitivity had been at the upper limit of the 95\% CI (i.e. 70\%), with the observed prevalence of true allergy (3.2\%) PST would still need to be performed in 39 patients in order to prevent a single mild reaction on challenge.

The main strength of the study stems from its robust methodology, which completely eliminates potential risks of verification and interpretation bias and allows for an impartial confirmation of previous estimates. The scarcity of true allergy in the pediatric population with a history of non-severe cutaneous reaction was also confirmed. The downside is that the low event rate also leads to large confidence interval around estimates. This phenomenon is further aggravated when excluding accelerated reactions, with a sensitivity estimate of $33 \%$ and a $95 \%$ confidence interval of 0.8 to $90.5 \%$. Future studies will need to be conducted in populations with higher rates of true allergy to improve the precision of these estimates.

The study also underscores the lack of reliability of skin testing, best exemplified by a patient with a discordant positive result to low concentration of PPL and negative result to a high concentration of PPL. Because, allergy skin test sizes are known to vary with repeat testing, some studies have performed these in triplicate to improve reliability. Such an approach would not however be representative of real-life practice, where tests are not replicated. If they were, the improved diagnostic accuracy would then have to be interpreted in light of the increased cost of reagents.

One limitation of this study is the lack of intradermal testing with amoxicillin, which is not available in its injectable form in Canada. One could assume that adding amoxicillin could have increased test sensitivity, although this was not systematically the case in other studies including it [1,5-8]. Addition of reagents the PST panel is also bound to decrease test specificity and increase cost of testing, which needs to be taken into consideration.

Although most international guidelines continue to recommend systematic PST for the assessment of penicillin allergy, recent guidelines from Canada [12] and the UK [13] argue against skin testing in children at low risk for penicillin allergy, especially in those with nonimmediate reactions which are often the result of the underlying infectious process rather than true drug hypersensitivity. This study has important implications, since it suggests that in children with nonsevere 
Table 2 Participants with positive intra-dermal skin tests

\begin{tabular}{|c|c|c|c|c|c|c|c|c|}
\hline \multirow[t]{3}{*}{ Sex } & \multirow[t]{3}{*}{ Age (years) } & \multirow{3}{*}{$\begin{array}{l}\text { Delay } \\
\text { since reaction } \\
\text { (years) }\end{array}$} & \multirow[t]{3}{*}{ Culprit drug } & \multirow{2}{*}{\multicolumn{2}{|c|}{$\frac{\mathrm{BP}(\mathrm{mm})}{\mathrm{IU} / \mathrm{mL}}$}} & \multirow[t]{3}{*}{ PPL (mm) } & \multirow[t]{3}{*}{ NS (mm) } & \multirow[t]{3}{*}{ DPT } \\
\hline & & & & & & & & \\
\hline & & & & $10^{4}$ & $10^{3}$ & & & \\
\hline \multicolumn{9}{|c|}{ True positive } \\
\hline$F$ & 8 & 0.7 & $\mathrm{AXO}$ & 5 & - & - & - & $\begin{array}{l}\text { Urticaria and } \\
\text { angioedema }<1 \mathrm{~h} \\
\text { post-DPT }\end{array}$ \\
\hline \multicolumn{9}{|c|}{ False positives } \\
\hline M & 5 & 1.3 & $\mathrm{AXO}$ & 8 & - & - & - & - \\
\hline M & 2 & 0.6 & $\mathrm{AXO}$ & 7 & - & - & - & - \\
\hline $\mathrm{F}$ & 5 & 1.0 & $\mathrm{AXO}$ & 6 & - & - & - & - \\
\hline $\mathrm{F}$ & 10 & 9.2 & $\mathrm{AXO}$ & 5 & - & - & - & - \\
\hline M & 11 & 5.7 & $\mathrm{AXO}$ & 4 & - & - & - & - \\
\hline M & 2 & 0.5 & $\mathrm{AXO}$ & 7 & - & - & - & - \\
\hline M & 2 & 0.7 & $\mathrm{AXO}$ & 4 & - & - & - & - \\
\hline M & 3 & 1.8 & $\mathrm{AXO}$ & 7 & - & - & - & - \\
\hline M & 2 & 0.5 & $\mathrm{AXO}$ & 8 & 4 & - & - & - \\
\hline M & 11 & 6.3 & $\mathrm{AXO}$ & 6 & 9 & - & - & - \\
\hline $\mathrm{F}$ & 18 & 17.6 & $\mathrm{AXO}$ & 3 & 3 & 5 & - & - \\
\hline $\mathrm{F}$ & 13 & 11.6 & $\mathrm{AXO}$ & 10 & - & 8 & 5 & - \\
\hline $\mathrm{F}$ & 2 & 1.0 & CLAV & - & 3 & 4 & - & - \\
\hline M & 17 & 11.3 & $\mathrm{AXO}$ & - & - & 5 & - & - \\
\hline M & 2 & 0.2 & $\mathrm{AXO}$ & - & - & 7 & - & - \\
\hline \multicolumn{9}{|c|}{ False negatives } \\
\hline $\mathrm{F}$ & 2 & 0.4 & $\mathrm{AXO}$ & - & - & - & - & Urticaria $<1$ h post-DPT \\
\hline M & 2 & 0.5 & $\mathrm{AXO}$ & - & - & - & - & Urticaria $<1$ h post-DPT \\
\hline $\mathrm{F}$ & 3 & 1.8 & $\mathrm{AXO}$ & - & - & - & - & Urticaria at $24 \mathrm{~h}$ post-DPT \\
\hline $\mathrm{F}$ & 2 & 0.7 & $\mathrm{AXO}$ & - & - & - & - & Urticaria at $12 \mathrm{~h}$ post-DPT \\
\hline
\end{tabular}

$B P$ benzylpenicillin, $P P L$ penicilloyl-polylysine, $N S$ normal saline, DPT drug provocation test, MDM; $A X O$ amoxicillin, CLAV amoxicillin + clavulinic acid

amoxicillin allergy, including proven IgE-mediated reactions, skin testing does not seem to be an effective screening tool. Consequently, these patients might benefit from undergoing a direct graded DPT, without prior skin testing.

In conclusion, using a novel double-blinded skintesting approach, this study was able to validate the poor accuracy of PST for the diagnosis of amoxicillin allergy, while controlling for verification and interpretation bias. This further supports the futility of PST prior to amoxicillin provocation in this population.

\section{Abbreviations}

BP: Benzylpenicillin; IgE: Immunoglobulin E; NPV: Negative predictive value; PPL: Penicilloyl-polylysine; PPV: positive predictive value; PST: Penicillin skin testing.

\section{Acknowledgements}

The authors would like to acknowledge Lucie Lavallée, RN, Annie Flibotte, RN and Claude Belleville, RN for their participation in the double-blinded penicillin skin testing. This study was enabled by grant support from the
Canadian Allergy, Asthma and Immunology Foundation and philanthropic donation from the Seigneur Family Foundation.

\section{Authors' contributions}

RL and PB were responsible for data collection, data analysis, and writing the manuscript. LP, JP, PB and ADR conceptualized the study design and wrote the study protocol. LP, KS, JLB and ADR were responsible for patient recruitment, patient care, and data entry. All authors discussed the results and contributed to the final manuscript. All authors read and approved the final manuscript.

\section{Funding}

No funding was received for this study.

\section{Availability of data and materials}

The authors confirm that the data supporting the findings of this study are available within the article.

\section{Ethics approval and consent to participate}

This study received approval from the CHU Sainte-Justine's ethics committee (CHUSJ-2013-495-3635). All patients signed informed consent forms prior to their enrollment.

\section{Consent for publication}

Not applicable. 


\section{Competing interests}

The authors report no conflicts of interest pertaining to the submitted work. $A D$ reports grants from Merk and ALK outside the submitted work. PB reports personal fees from Novartis, Pfizer, Sanofi, ALK and Aralez, as well as grants from DBV technologies, Regeneron and Sanofi outside the submitted work.

\section{Author details}

${ }^{1}$ Pediatric Allergy and Clinical Immunology, CHU Sainte-Justine, Montreal, Canada. ${ }^{2}$ Allergy and Clinical Immunology, Centre Hospitalier de I'Université de Montréal (CHUM), 3175 Chemin de la Côte-Sainte-Catherine, Montreal, QC H3T 1C5, Canada.

Received: 3 May 2020 Accepted: 4 June 2020

Published online: 01 July 2020

\section{References}

1. Ibanez MD, Rodriguez Del Rio P, Lasa EM, et al. Prospective assessment of diagnostic tests for pediatric penicillin allergy: from clinical history to challenge tests. Ann Allergy Asthma Immunol. 2018;121(2):235-44.

2. Hartman $\mathrm{H}$, Schneider $\mathrm{K}$, Hintermeyer $\mathrm{M}$, et al. Lack of clinica hypersensitivity to penicillin antibiotics in common variable immunodeficiency. J Clin Immunol. 2017:37(1):22-4.

3. Vyles D, Adams J, Chiu A, Simpson P, Nimmer M, Brousseau DC. Allergy testing in children with low-risk penicillin allergy symptoms. Pediatrics. 2017;140:2.

4. Confino-Cohen R, Rosman Y, Meir-Shafrir K, et al. Oral challenge without skin testing safely excludes clinically significant delayed-onset penicillin hypersensitivity. J Allergy Clin Immunol Pract. 2017;5(3):669-75.

5. Caubet JC, Kaiser L, Lemaitre B, Fellay B, Gervaix A, Eigenmann PA. The role of penicillin in benign skin rashes in childhood: a prospective study based on drug rechallenge. J Allergy Clin Immunol. 2011;127(1):218-22.
6. Barni S, Mori F, Sarti L, et al. Utility of skin testing in children with a history of non-immediate reactions to amoxicillin. Clin Exp Allergy. 2015:45(9):1472-4.

7. Mori F, Cianferoni A, Barni S, Pucci N, Rossi ME, Novembre E. Amoxicillin allergy in children: five-day drug provocation test in the diagnosis of nonimmediate reactions. J Allergy Clin Immunol Pract. 2015;3(3):375-80.

8. Tubili F, Angelucci C, Butti D, Barni S, Mori F, Novembre E. Allergologic work-up un diagnosing amoxicillin hypersensitivity in children. Medico e Bambino. 2013:32:446-52.

9. Mill C, Primeau MN, Medoff E, et al. Assessing the diagnostic properties of a graded oral provocation challenge for the diagnosis of immediate and nonimmediate reactions to amoxicillin in children. JAMA Pediatr. 2016;170(6):e160033.

10. Begin P, Graham F, Killer K, Paradis J, Paradis L, Des Roches A. Introduction of peanuts in younger siblings of children with peanut allergy: a prospective, double-blinded assessment of risk, of diagnostic tests, and an analysis of patient preferences. Allergy. 2016;71(12):1762-71.

11. Joint Task Force on Practice P, American Academy of Allergy A, Immunology. Drug allergy: an updated practice parameter. Ann Allergy Asthma Immunol. 2010;105(4):259-73

12. Wong T, Atkinson A, Jong G, Rieder MJ, Chan ES, Abrams EM. Betalactam allergy in the paediatric population. Paediatr Child Health. 2020;25(1):62-3.

13. Mirakian R, Leech SC, Krishna MT, et al. Management of allergy to penicillins and other beta-lactams. Clin Exp Allergy. 2015;45(2):300-27.

\section{Publisher's Note}

Springer Nature remains neutral with regard to jurisdictional claims in published maps and institutional affiliations.
Ready to submit your research? Choose BMC and benefit from:

- fast, convenient online submission

- thorough peer review by experienced researchers in your field

- rapid publication on acceptance

- support for research data, including large and complex data types

- gold Open Access which fosters wider collaboration and increased citations

- maximum visibility for your research: over $100 \mathrm{M}$ website views per year

At BMC, research is always in progress.

Learn more biomedcentral.com/submissions 